\title{
Tibial Mononeuropathy from a Lower Limb Synovial Cyst
}

\author{
J.C.L. Sun, C. Wallace and D.W. Zochodne
}

\begin{abstract}
Background: Tibial mononeuropathy due to compression by a synovial cyst is uncommon with fewer than 10 cases reported in the literature. Method: Case Study. Results: Tibial motor mononeuropathy with focal conduction block between the popliteal fossa and ankle was identified by electrophysiological testing. Magnetic resonance imaging and surgical exploration identified a synovial cyst compressing the nerve just distal to the popliteal fossa. Conclusions: The combination of electrophysiological localization and imaging in cases of unexplained tibial mononeuropathy may identify an unexpected structural cause.
\end{abstract}

RÉSUMÉ: Mononeuropathie du nerf sciatique poplité interne due à un kyste synovial du membre inférieur. Introduction: La mononeuropathie du nerf sciatique poplité interne due à une compression par un kyste synovial est peu fréquente, la littérature faisant état de dix cas seulement. Méthode: Étude de cas. Résultat: Une mononeuropathie du nerf sciatique poplité interne avec bloc de conduction en foyer entre le creux poplité et la cheville a été identifiée par une étude électrophysiologique. Un kyste synovial comprimant le nerf au-dessous du creux poplité a été identifié par imagerie par résonance magnétique et lors de la décompression chirurgicale. Conclusion: La localisation électrophysiologique combinée à l'imagerie dans les cas de mononeuropathie du nerf sciatique poplité interne peut identifier une cause structurale inattendue.

Can. J. Neurol. Sci. 1995; 22: 312-315

Tibial mononeuropathy originating at the knee is uncommon. When it is encountered without apparent trauma one must consider compression of the nerve by a synovial cyst, ${ }^{1.5}$ a ganglion of the tibial nerve, ${ }^{6.7}$ compression by the tendinous arch of the soleus muscle, ${ }^{8.9}$ compression by fibrous bands between the two heads of gastrocnemius muscle $\mathrm{e}^{10,11}$ and tibial nerve tumours. ${ }^{12-15}$ Electrophysiological investigations can assist in determining the level of the lesion. In addition magnetic resonance imaging (MRI) may identify a structural cause in cases of unexplained tibial mononeuropathy.

We present a case of acute tibial mononeuropathy secondary to entrapment by a synovial cyst that presented with evidence of focal conduction block between the popliteal fossa and ankle.

\section{Case Report}

A 32-year-old man complained of an eighteen month history of right sole numbness after jogging and recent more diffuse right thigh and calf discomfort. His sole numbness typically occurred after forty-five minutes of jogging and would resolve within minutes of cessation. Ten days prior to evaluation while jogging he developed sole numbness, similar to previous episodes. However the following day he noted diffuse discomfort over his right thigh and calf. The symptoms became progressively more intense over the next few days. He also noticed an inability to flex his right toes. Four days later he developed persistent numbness of his right sole.

On examination he was unable to flex and had difficulty abducting his right toes. Motor power in the other muscle groups of his lower extremities was normal. His right ankle reflex was reduced and could only be elicited with reinforcement. There was a sensory deficit to light touch and pinprick over the plantar surface of his right foot that extended up to involve part of the medial ankle. Manual compression of the right popliteal fossa produced dysesthesia in his toes but no popliteal mass was palpable.

A computed tomographic $(\mathrm{CT})$ myelogram of the lumbar intraspinal space was normal. He was referred for neurophysiological evaluation. Electrophysiological studies were carried out (Table 1) using standardized techniques. Motor " $M$ " potentials were recorded using surface electrodes (extensor digitorum brevis for the peroneal nerve; abductor hallucis for the tibial nerve). In tibial fibres the amplitude of the " $\mathrm{M}$ " potential recorded from ankle stimulation on the symptomatic right side was less than $50 \%$ of that on the contralateral side (Figure 1). There was a $>80 \%$ decline in the amplitude of the " $M$ " potential between the ankle and popliteal stimulating sites, indicating conduction block. Other conduction studies were normal beyond asymmetry in the medial plantar responses (lower on the right). Needle electrode study of right abductor hallucis identified occasional positive sharp waves without fibrillations and no voluntary motor unit potentials were recruited. Right medial head of gastrocnemius was normal. MRI of the right lower leg showed a multilocular cyst within the inferior popliteal fossa which did not communicate with either the femorotibial or tibiofibular joints (Figures 2 and 3). The lesion was hyperintense on the T2-weighted image and hypointense on the $\mathrm{T} 1$-weighted image. No intra-articular pathology was demonstrated.

This patient underwent surgical decompression of the popliteal cyst twenty days after our initial evaluation. The cyst was identified at surgery distal and lateral to the knee attached to the posterior tibia, popliteus muscle and soleus muscle. There was extension of the cyst

From the Department of Clinical Neurosciences, The University of Calgary, Calgary. RECEIVED MARCH 27, 1995. ACCEPTED IN FINAL FORM JUNE 7, 1995.

Reprint request to: Dr. D.W. Zochodne, Department of Clinical Neurosciences, 3330 Hospital Drive N.W., Calgary, Alberta, Canada T2N 4N1 
Table 1: Electrophysiological Results.

\begin{tabular}{lll}
\hline Nerve & Amplitude & Conduction Velocity \\
\hline Right tibial ankle & $8.7 \mathrm{mV}$ & \\
\hline \multicolumn{1}{c}{ knee } & $1.8 \mathrm{mV}$ & $41 \mathrm{~m} / \mathrm{s}$ \\
\hline Left tibial ankle & $24 \mathrm{mV}$ & \\
\hline \multicolumn{1}{c}{ knee } & $20 \mathrm{mV}$ & $43 \mathrm{~m} / \mathrm{s}$ \\
\hline Right medial plantar & $27 \mu \mathrm{V}$ & $50 \mathrm{~m} / \mathrm{s}$ \\
\hline Left medial plantar & $39 \mu \mathrm{V}$ & $40 \mathrm{~m} / \mathrm{s}$ \\
\hline Right peroneal (ankle) & $14.8 \mathrm{mV}$ & \\
\hline Left peroneal (ankle) & $9.0 \mathrm{mV}$ & \\
\hline Right sural & $26 \mu \mathrm{V}$ & $45 \mathrm{~m} / \mathrm{s}$ \\
\hline
\end{tabular}

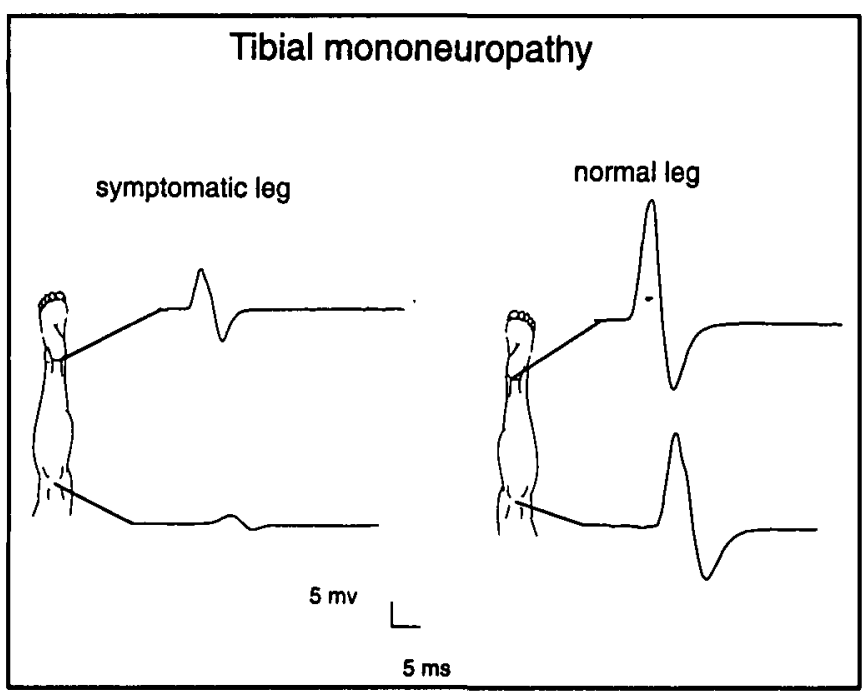

Figure 1: Motor conduction studies of the tibial nerves (recording over abductor hallucis). The symptomatic right side has a smaller distally evoked $M$ potential and conduction block between the knee and ankle.

into the deep calf, communication with the knee joint through the popliteus hiatus and the cyst contained clear yellowish viscous fluid. The histopathological diagnosis was of a benign synovial cyst. Postoperatively, the patient developed severe pain and burning in his right sole and heel. By 2 months postoperatively the pain had settled and he had noted some recovery of toe flexion and abduction. The sensory findings were unchanged.

Electrophysiological studies two weeks and 2 months following surgery identified a further decline in the amplitude of the right tibial " $M$ " potential recruited from the ankle with evidence of denervation in abductor hallucis. Conduction block was not observed.

\section{Discussion}

Synovial cysts with possible tibial nerve compression should be suspected in patients who complain of unilateral posterior knee pain and pain or paresthesia involving the heel and sole of the foot, especially if they have a history of degenerative joint disease or other pathological knee conditions. These symptoms can be aggravated by activity, as in our case, and can occasionally be bilateral. ${ }^{3}$ On examination patients may have weak flexion

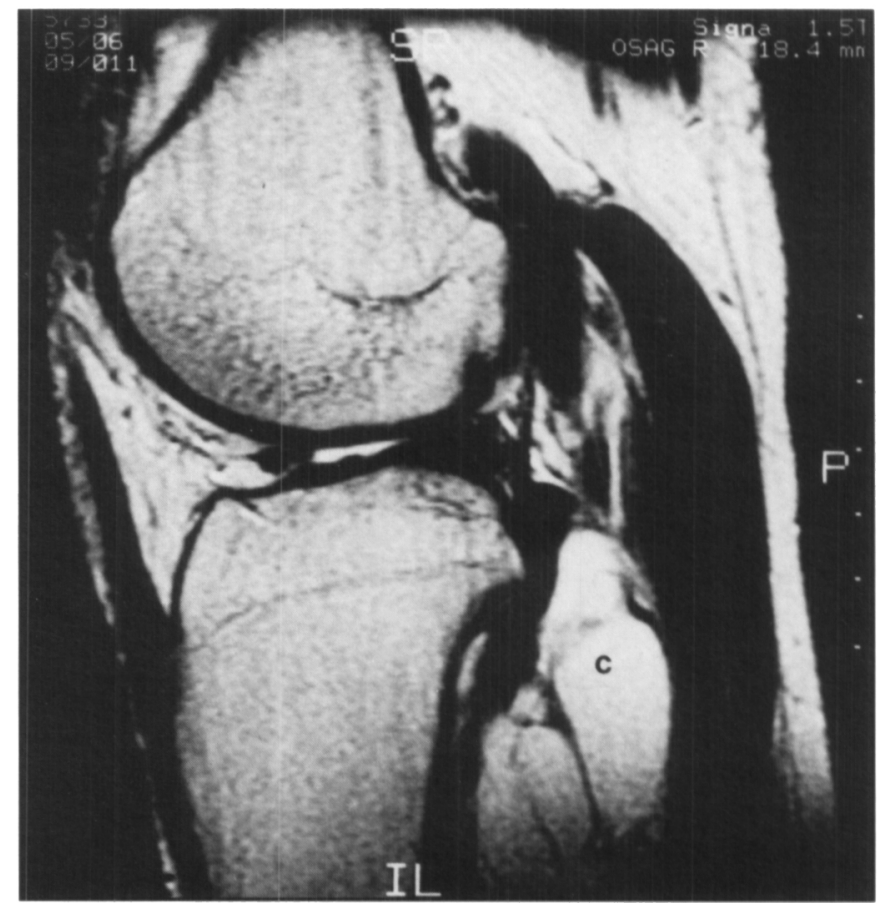

Figure 2: Sagittal FSE T2-weighted MR image (TR 2200, TE 84). A septated hyperintense mass is seen in the posterior midline, between the gastrocnemius and popliteus muscles, just inferior to the level of the knee joint (" $c$ " indicates cyst).

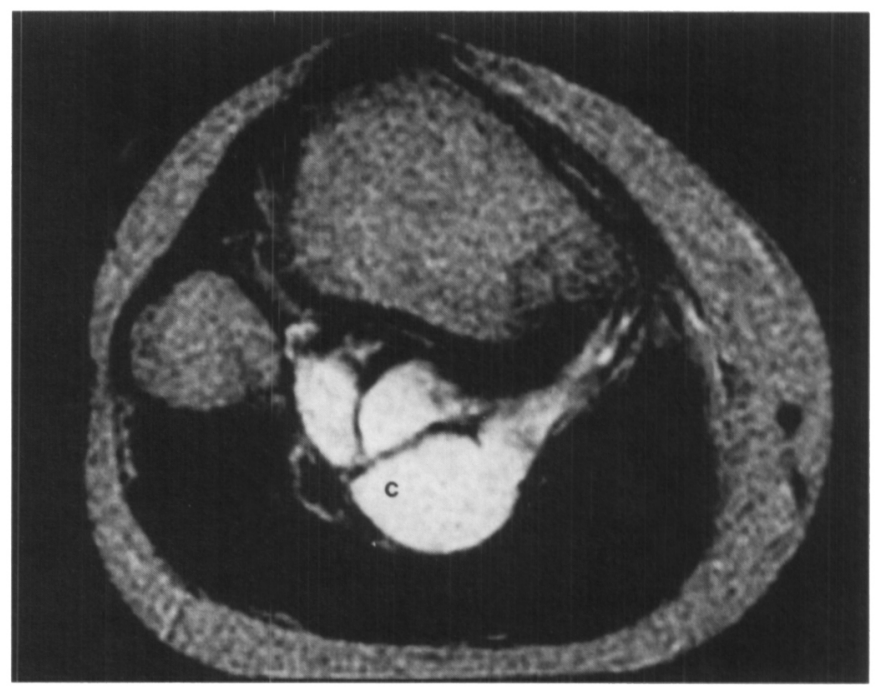

Figure 3: Axial T2-weighted image (TR 3600, TE 102). The mass, indicated by the letter " $c$ " is seen to be of water intensity. There is displacement of the neurovascular bundle (ring-like area just left of the cyst).

and abduction of the toes on the involved side. Weak ankle plantar flexion may occur if the level of compression involves branches to the gastrocnemius and soleus muscles. A reduced ankle reflex and sensory deficits on the plantar surface of the foot are often present. Patients may have a tender palpable popliteal mass and on occasion manual compression of the popliteal fossa may produce sensory symptoms in the foot (Table 2). Popliteal (Baker) cysts are most commonly located 
Table 2: Cases of tibial mononeuropathies caused by synovial cyst.

\begin{tabular}{|c|c|c|c|}
\hline Authors & age/sex & symptoms & signs \\
\hline Groulier et al., 1987 (1) & $57 \delta$ & - sole dysaesthesiae & $\begin{array}{l}\text { - left sided involvement } \\
\text { - weakness of toe flexors } \\
\text { - tarsal tunnel Tinel's sign }\end{array}$ \\
\hline Kashani et al., 1985 (2) & $60 \%$ & $\begin{array}{l}\text { - posterior knee pain } \\
\text { - plantar surface paraesthesia }\end{array}$ & $\begin{array}{l}\text { - right sided involvement } \\
\text { - degenerative joint disease } \\
\text { - palpable popliteal mass } \\
\text { - absent toe flexion } \\
\text { - reduced ankle reflex } \\
\text { - plantar surface sensory deficit }\end{array}$ \\
\hline Zygmunt et al., 1982 (3) & 55 के & - knee pain & $\begin{array}{l}\text { - bilateral involvement } \\
\text { - Rheumatoid Arthritis } \\
\text { - palpable popliteal mass } \\
\text { - sensory deficit on the plantar surface of the } \\
\text { 4th \& 5th toes }\end{array}$ \\
\hline Nakano et al., 1978 (4) & $51-66$ (3 patients) & $-n / a$ & $\begin{array}{l}\text { - Rheumatoid Arthritis } \\
\text { - painful palpable popliteal mass } \\
\text { - weakness in all muscles supplied by the } \\
\text { tibial nerve } \\
\text { - absent ankle reflex } \\
\text { - sensory deficit in tibial nerve distribution } \\
\text { - peroneal nerve involvement }\end{array}$ \\
\hline current case & $32 \delta$ & $\begin{array}{l}\text { - plantar surface paresthesia } \\
\text { - right thigh and calf discomfort } \\
\text { - aggravated by exercise }\end{array}$ & $\begin{array}{l}\text { - right sided involvement } \\
\text { - absent toe flexion and abduction } \\
\text { - reduced ankle reflex } \\
\text { - plantar surface and medial ankle sensory } \\
\text { deficit } \\
\text { - dysesthesia of toes upon compression of the } \\
\text { popliteal fossa }\end{array}$ \\
\hline
\end{tabular}

n/a - not available

in the semimembranosus-semitendinosus bursa, in the medial aspect of the popliteal fossa between the medial head of the gastrocnemius muscle and the semimembranosus tendon. These cysts are usually associated with internal derangement of the knee joint with chronic effusion causing distention of the bursa.

In this case, no communication with the joint space was seen, and no intra-articular pathology was demonstrated; also the location of the synovial cyst was unusual in that it was situated in the posterior midline, deep to the gastrocnemius muscle.

If the lesion is uncertain a CT myelogram may help to rule out sacral plexopathy or S1 and S2 radiculopathies. ${ }^{16}$ It is also important to rule out tarsal tunnel compression with electrophysiological studies.

Our patient likely had mild compression of the tibial nerve during the eighteen months that he experienced his initial symptoms. His acute deterioration may have represented sudden mechanical damage of the tibial nerve, partial cyst rupture or expansion of the cyst. Focal conduction block of the tibial motor "M" potential localized the lesion to the popliteal fossa-ankle nerve segment distal to branches supplying the gastrocnemius muscle. The conduction block prompted MRI studies of the leg which identified the structural cause of the neuropathy.

There was likely both segmental demyelination and axonal degeneration attributable to the lesion we report. The presence of conduction block indicated probable segmental demyelination of tibial motor fibres. Loss of " $M$ " potential and positive waves in abductor hallucis identified early denervation likely secondary to axonal degeneration. The reduced medial plantar response suggested axonal degeneration of sensory fibres.

Treatment of tibial mononeuropathy secondary to compression by a synovial cyst can consist of surgical decompression, as in our case, or knee joint aspiration and intra-articular prednisone injection. ${ }^{2,4}$ Our patient had clinical and electrophysiological deterioration postoperatively possibly secondary to the postoperative inflammation and repair with further axonal injury or intraoperative nerve ischemia.

\section{ACKNOWLEDGEMENTS}

Heather Price provided expert secretarial assistance. D.W. Zochodne is a Medical Scholar of the Alberta Heritage Foundation for Medical Research.

\section{REFERENCES}

1. Groulier P, Benaim JL, Curvale G, et al. Un cas de compression du nerf tibial postérieur par un kyste synovial développé aux dépens de l'articulation pérenéo-tibiale supérieure. Rev Chir Orthop Reparatrice Appar Mot 1987; 73(1): 67-69.

2. Kashani SR, Moon AH, Gaunt WD. Tibial nerve entrapment by a Baker cyst: case report. Arch Phys Med Rehabil 1985; 66(1): 49-51.

3. Zygmunt S, Keller K, Lidgren L. Baker cyst causing nerve entrapment. Scand J Rheumatol 1982; 11: 239-240. 
4. Nakano KK. Entrapment neuropathy from Baker's cyst. JAMA 1978; 239(2): 135.

5. Maezono M, Araki M, Iwano K. Case of tibial nerve palsy caused by Baker's cyst. Iryo 1967; 21: 1479-1482.

6. Mahaley MS Jr. Ganglion of the posterior tibial nerve. J Neurosurg 1974; 40: 120-124.

7. Friedlander HL. Intraneural ganglion of the tibial nerve. J Bone Joint Surg Am 1967; 49: 519-522.

8. Mastaglia FL, Venerys J, Stokes BA, et al. Compression of the tibial nerve by the tendinous arch of origin of the soleus muscle. Clin Exp Neurol 1981; 18: 81-86.

9. Costigan D, Tindall S, Rossi J, et al. Tibial nerve entrapment by the tendinous arch of origin of the soleus muscle: diagnostic difficulties. Muscle and Nerve 1991; 14: 880.

10. Psathakis D, Psathakis N. Popliteal compression syndrome: an overproportional incidence. Vasa 1991; 20: 256-260.
11. Podore PC. Popliteal entrapment syndrome: a report of tibial nerve entrapment. J Vasc Surg 1985; 2: 335-336.

12. Cantos-Melian B, Arriaza-Loureda R, Aisa-Varela P. Tibialis posterior nerve schwannoma mimicking achilles tendinitis: ultrasonographic diagnosis. J Clin Ultrasound 1990; 18: 671-673.

13. Iyer VG, Garretson HD, Byrd RP, Reiss SJ. Localized hypertrophic mononeuropathy involving the tibial nerve. Neurosurgery 1988 ; 23: 218-221.

14. Bilbao JM, Khoury NJS, Hudson AR, Briggs SJ. Perineurioma (localized hypertrophic neuropathy). Arch Pathol Lab Med 1984; 108: 557-560.

15. Mitsumoto $\mathrm{H}$, Wilbourn AJ, Goren $\mathrm{H}$. Perineurioma as the cause of localized hypertrophic neuropathy. Muscle Nerve 1980;3:403-412.

16. Stewart JD. The tibial, plantar, interdigital and sural nerves. In: Focal Peripheral Neuropathies, 2nd Edition. New York: Raven Press, 1993: 367-385. 